\title{
ПРОБЛЕМЫ И ПЕРСПЕКТИВЫ ГЕОПРОСТРАНСТВЕННЫХ ДАННЫХ ПРИ ВНЕДРЕНИИ В ЦИФРОВУЮ ЭКОНОМИКУ ДЛЯ УПРАВЛЕНИЯ ТЕРРИТОРИЯМИ
}

\section{Сергей Михайлович Кузнецов}

Сибирский государственный университет геосистем и технологий, 630108, Россия, г. Новосибирск, ул. Плахотного, 10, аспирант, тел. (913)954-81-20, e-mail: serega_54_rus94@mail.ru

\section{Олеся Игоревна Малыгина}

Сибирский государственный университет геосистем и технологий, 630108, Россия, г. Новосибирск, ул. Плахотного, 10, кандидат технических наук, доцент кафедры кадастра и территориального планирования, тел. (913)000-13-32, e-mail: 131379@mail.ru

Развитие применения геопространственнх данных с использованием концепции интернета вещей является перспективным направлением, в котором уже начали работу ведущие компании в области геоинформационных услуг. В статье рассмотрены проблемы и перспективы геопространственных данных при внедрении в цифровую экономику для управления территориями. Особое внимание уделено программе «Цифровая экономика Российской Федерации», а также проблемам связанным с принятием управленческих решений: сокращением технических, политических и организационных барьеров.

Ключевые слова: геопространственные технологии, цифровая экономика, управление территориями, геопорталы, большие данные, проблемы внедрения

\section{PROBLEMS AND PROSPECTS OF GEOSPATIAL DATA IN THE IMPLEMENTATION OF THE DIGITAL ECONOMY FOR TERRITORY MANAGEMENT}

\section{Sergei M. Kuznecov}

Siberian State University of Geosystems and Technologies, 10, Plakhotnogo St., Novosibirsk, 630108, Russia, Ph. D. Student, phone: (913)954-81-20, e-mail: serega_54_rus94@mail.ru

\section{Olesya I. Malygina}

Siberian State University of Geosystems and Technologies, 10, Plakhotnogo St., Novosibirsk, 630108, Russia, Ph. D., Associate Professor, Department of Cadastre and Territorial Planning, phone: (913)000-13-32, e-mail: 131379@mail.ru

The development of the application of geospatial data using the concept of the Internet of things is a promising area in which leading companies in the field of geoinformation services have already started working. The article discusses the problems and prospects of geospatial data in the implementation of the digital economy for the management of territories. Special attention is paid to the program "Digital economy of the Russian Federation", as well as problems related to management decision-making: reducing technical, political and organizational barriers.

Keywords: geospatial technologies, digital economy, territory management, geoportals, big data, implementation issues

В современных реалиях геопространственные данные используются в большинстве информационных процессов и системах в государственном управлении территориями, взаимодействии государства с гражданами и различными социальными структурами, бизнес-процессах и текущей жизнедеятельности государства. 
Пространственные данные сегодня позволяют решать жизненно важные для государства задачи, имеют высокий потенциал для развития экономики и улучшения инвестиционного климата, служат основой цифровой трансформации отраслей [6].

В результате постоянного совершенствования сферы получения и использования пространственных данных повышается качество инфраструктуры, результативность процессов по управлению территориями. Внедрение этих процессов в цифровизацию экономики требует постоянных изменений в технологиях производства и использования пространственных данных. В настоящее время уже недостаточно использовать определенный вид данных как основной инструмент работы с информацией, управленческий состав должен уметь анализировать и использовать наборы таких данных [2].

В настоящее время во многих странах с развитой изифровой экономикой около 70\% государственных и предпринимательских управленческих решений принимаются на основе геопространственных данных. Создание и совериенствование необходимой инфраструктуры проходит при помощи мощзной государственной поддержки и финансирования.

Правительство России разработало государственную программу развития uุифровой экономики «Цифровая экономика Российской Федерации», которая должна к 2024 году привести к созданию большого и значимого сектора экономики, в котором на первое место долэнн выйти развитие геоинформационных технологий и использование геопространственных данных для устойчивого экономического и соцчиального развития государства [1].

Для управления развитием цифровой экономики в России была сформирована «дорожная карта». В «дорожной карте» выделены 3 основных этапа развития направлений цифровой экономики, по итогам которых предусмотрено достижение целевого состояния по каждому из направлений, в которых упоминаются геопространственные данные и их использование.

Задачи 4.14 и 4.15 программы «Цифровая экономика Российской Федерации» непосредственно касаются пространственных данных:

- 4.14. Создать отечественную цифровую платформу сбора, обработки и распространения пространственных данных для нужд картографии и геодезии, обеспечивающую потребности граждан, бизнеса и власти;

- 4.15. Создать отечественную цифровую платформу сбора, обработки, хранения и распространения данных, дистанционного зондирования Земли, обеспечивающую потребности граждан, бизнеса и власти (проект «Цифровая Земля» из космоса) [7].

Для описания современного блока геопространственных данных о территории требуется огромнылй массив разнородной информации. При этом речь идёт не только о «больших данных», но и о «умной» информации, которая в свою очередь включает данные «умной» инфраструктуры в разрезе «умных городов» с последующим делением на «умные дома» созданные с помощью современных цифровых технологий. Таким образом возникает замкнутая цепочка 
использования и передачи геопространственной информации, охватывающей все структурные единицы территрии, помогающие при её анализе и принятии решений.

Сейчас основные потребители геопространственных данных - федеральные и региональные органы власти, муниципалитеты и крупные хозяйствующие субъекты. Как правило бюджет этих органов ограничен различными государственными и финансовыми ограничениями на получение таких данных, а также квалифицированных специалистов для их обработки. Обмен и обработка такими данными затруднена в силу разрозненности программного обеспечения и невозможности использования полученных данных повторно. Именно сейчас необходимо в рамках программы «Цифровая экономика Российской Федерации» создать рабочую систему использования геопространственных данных в единой государственной системе получения, анализа и использования таких данных для нужд всех областей цифровой экономики [2].

Необходимость принятия оправданных решений на основе актуальной и достоверной информации, а часто и в реальном времени является основным толчком для улучшения существующих компьютерных приложений (как отечественных так и зарубежных адаптированных) и разработки новых систем. Как следствие мы должны наблюдать рост и развитие данного сектора использования геопространственных данных с ростом и разнообразием программного обеспечения.

После активного внедрения геопространственных данных в различные области цифровой экономики мы можем получить большую выгоду и прибыль от комбинации источников новых, свободных и открытых геопространственных данных. Все это позволит вывести на новый уровень качество услуг и получаемой информации, для управления и анализа, как для государственных органов надзора и управления, так и для отдельных граждан. Кроме этого должно быть налажено активное взаимодействие между поставщиками таких данных и их пользователями, для того чтобы система цифровой экономики не работала в одностороннем порядке, а гибко подстраивалась под реалии современных экономических потребностей потребителей и отвечала современным запросом всех структур пользователей для управления территориями нашей страны.

Полученные источники новых геопространственных данных, часто революционных данных в силу своей новизны и востребованности, дают возможность решить широкий спектр социальных проблем в управлении территориями и несут экономические выгоды как правило для всех отраслей экономики и социальной жизни.

Одним из перспективных направлений для развития применения геопространственнх данных в цифровой экономике России возможно с использованием современных технологий. Одним из примеров такой технологии является - интернет вещей [3]. Это уже не новое, но довольно перспективное направление в нашей стране, в котором уже начали работу ведущие компании в области предоставления геоинформационных услуг. Получение данных не только от БПЛА, Д33, лазерного сканирования и других устоявшихся технологий несомненно приносит достаточное количество необходимой геопространственной 
информации, но с развитием новых трендов и технологий мы должны внедрять и новые, на первый взгляд не сильно специализированные для этой области продукты. Новые продукты помогают получать не только глобальную геопространственную информацию, но и локальную относящуюся к небольшим участкам территории, где-то просто точечных объектов. Все это позволяет поднять эффективность использования территориальных объектов.

Развитие муниципальных и городских сетей различного рода связи и увеличения количества отечественных центров обработки геопространственных данных, а также подключение к интернету вещей всех социально значимых объектов управления будет способствовать тому что мы сократим, а в последствии и устраним цифровое неравенство между Российскими регионами и муниципальными образованиями. В дальнейшем также возможно обеспечить все потребности отдельных пользователей, домохозяйств, бизнеса и органов власти геопространственной информацией и данными для использования в управлении различной инфраструктурой с использованием высокоскоростного интернета для беспрепятственной передачи больших объёмов геопространственных данных.

Российская и зарубежная практика получения и внедрения современных геопространственных данных и технологий выявила ряд общих проблем, которые в нашей стране в основном связаны с использованием больших объёмов получаемых и передаваемых данных. Также исходя из вышесказанного мы видим проблему в анализе этих данных для задач управления территорий, которые влекут за собой снижение качества геопространственных данных и понимания важных и первостепенных задач в управлении для развития цифровой экономики Российской федерации, а также полноценную интеграцию геопространственных данных в управленческие системы различных органов власти и социальных организаций и различных сред.

Кроме того, существуют проблемы, связанные с принятием управленческих решений на местах (в организациях) связанных с увеличением регламентирующих документов большинства технических моментов получения и использования геопространственных данных, а также возможные политические, геополитические и организационные ситуации в стране связанные с конфиденциальностью и безопасностью использования имеющихся данных.

Возрастающая сложность городских систем, новые области инфраструктуры города и растущая взаимозависимость всех систем повышают уязвимость города при возможных сбоях системы или экстремальных погодных явлениях, а также несоответствие навыков на разных ступенях управления: Без умных людей, использующих смарт-планирование не решит проблему «умных» городов т «интернета вещей».

Опыт зарубежных стран показывает, что внедрение геопространственных технологий возможно только через организационную форму такую как государственно-частное партнёрство [5].

Зарубежные исследования показали, что, государственные инвестиции в геопространственную инфраструктуру внутри страны приносят значительные выгоды для цифровой экономики и потребиелей этой информации. 
В целом использование геопространственных данных в различных отраслях народного хозяйства при разработке системы цифровой экономики страны является в настоящее время весьма актуально и могут стать основным элементом большого технологического и управленческого скачка. Зарубежные исследования последних $2-3$ лет показали, что уровень доходности геопространственной индустрии сравним с доходностью игровой и мобильной индустрии, что позволяет привлекать в данную область большие инвестиции с гарантированной отдачей активов.

В докладе Федеральной службы государственной регистрации, кадастра и картографии и Национального исследовательского университета «Высшая школа экономики» «Пространственные данные: потребности экономики в условиях цифровизации» опубликованного в 2020году делается вывод, что в современных реалиях «Применение новых геопространственных технологий даёт возможность решить более амбициозную задачу - «от умного города к умной нации»»» [6].

\section{БИБЛИОГРАФИЧЕСКИЙ СПИСОК}

1. Антонов Е. С., Дубровский А. В., Подорожная А. А. Обзор характеристик спутниковых систем дистанционного зондирования, применяемых в кадастре, землеустройстве и мониторинге земель. - Регулирование земельно-имущественных отношений в России: правовое и геопространственное обеспечение, оценка недвижимости, экология, технологические решения : сб. материалов третьей национальной научно-практической конференции, 27-29 ноября 2019 г., Новосибирск. - Новосибирск: СГУГиТ, 2020. - С. 120-125.

2. Дубровский, А.В. Малыгина, О.И. Кузнецов, С.М. К вопросу о техническом регулировании в сфере геодезии, картографии и пространственных данных [Текст] Интерэкспо ГЕОСибирь. XVI Междунар. науч. конгр., 18 июня - 8 июля 2020 г., Новосибирск [Текст]: сб. материалов в 8 т. Т. 3: Национальная науч. конф. «Экономичеснкое развитие Сибири и Дальнего Востока. Экономика природопользоваия, землеустройство, лесоустройство, управление недвижимостью». - Новосибирск: СГУГиТ, 2020. № 2.- С. 3-11.

3. Жебровский С.И., Кузин Д.А., Стрельцова М.М. Обзор проблем и перспектив развития геоинформационных систем в эпоху всеобъемлющего интернета // Современные наукоемкие технологии. - 2018. - № 12-1. - С. 237-241.

4. Захаров Д. В. Цифровизация экономики: проблемы и перспективы // Развитие науки, национальной инновационной системы и технологий : сборник научных трудов по материалам Международной научно-практической конференции 13 мая 2020г. : Белгород : ООО Агентство перспективных научных исследований (АПНИ), 2020. С. 102-107.

5. Зобова Л.Л. Проблема описания геопространств: современные технологии // Вестник Кемеровского государственного университета. Серия: Политические, социологические и экономические науки. 2016. №1 (1).

6. Пространственные данные: потребности экономики в условиях цифровизации / Е. Б. Белогурова, В. Е. Воробьев, О. Г. Гвоздев и др.; Фед. служба гос. регистрации, кадастра и картографии; Нац. исслед. ун-т «Высшая школа экономики»; НИИ «АЭРОКОСМОС». - М.: НИУ ВШЭ, 2020. - 128 с.

7. Цифровая экономика в строительстве: перспективы 3D-геоданных - Режим доступа: https://www.bfm.ru/news/364943- Загл. с экрана.

(С) С. М. Кузнеияов, О. И. Мальицна, 2021 